\title{
A Influência do Comportamento Humano na Administração
}

WILMAR VIEIRA JATOBA

Técnico do Ministério do Planejamento e Coordenação Geral

A Administração, por integrar o conjunto das ciências sociais, tem sua dinâmica condicionada às flutuações do comportamento humano. A relatividade de valôres como, por exemplo, a eficiência dentro da Administração, é conseqüência daquelas flutuações, se não estiver exclusivamente ligada a causas puramente mecânicas. O nível de eficiência dos atos administrativos se coloca, pois, sempre na dependência do comportamento individual, mesmo consideradas as influências do mecanicismo que possam surgir na direção da ação do indivíduo, como participante de um processo. Quer dizer, o pêso do comportamento humano, das atitudes pessoais do indivíduo, é mais significativo, dentro da área administrativa, que sua sujeição a imperativos de ordem técnica, mecânica, ou puramente científica. Essa distinção entre a ciência social e a ciência pura dá a medida das dificuldades que enfrenta aquela em relação a esta.

Exemplo marcante da influência do comportamento humano pode ser citado, à quisa de esclarecimento. É o caso da pesquisa no campo social, que não exige dados concretos e mensuráveis em têrmos materiais. A participação ou a atitude do observador influi no resultado da pesquisa, enquanto que o cientista pode isolar o fato e estudá-lo sem o risco de ser levado a se integrar, como componente, no campo da pesquisa. A pesquisa científica também leva o observador a lidar com dados mais fàcilmente limitados e controlados, o que não ocorre com a pesquisa social. $O$ conjunto de conhecimentos aplicados à pesquisa cientifica é manipulado em têrmos exatos, fàcilmente mensuráveis e aplicáveis independentemente das condições usualmente encontradas pela pesquisa social. Razão por que há mais confiança e mais objetividade na pesquisa científica. 0 
pesquisador social tem a certeza de que lidará com valôres sujeitos às flutuações ditadas pela natureza humana, passíveis, portanto, de interpretações diversas e aplicabilidade variável. Um exemplo mais concreto que poderiamos lembrar é o que se refere à pesquisa dos fatôres que concorrem para o surgimento de um problema de caráter racial em determinada comunidade. No caso, é grande o risco de o observador ser levado a influenciar o resultado da pesquisa, como elemento humano cujas raízes sócio-culturais o induzam a uma tomada de posição predeterminada, o que traria à tona distorcida imagem do fato sociológico.

Examinado o problema sob êste prisma, terá a administração pública de se valer de instrumentos capazes de atenuar as conseqüências porventura danosas do comportamento humano, já que não as pode eliminar. Êsse fim só será colimado sob a ação do aperfeiçoamento das qualidades pessoais/funcionais da célula primordial do organismo governamental, que ainda é o homem. Sua formação e seu aperfeiçoamento, dentro da estrutura governamental, constituirão a melhor arma para defendê-lo contra a grande incidência do fator tecnolologia, bem assim para capacitá-lo a se adequar às exigências impostas pela sociedade industrial e, mais adiante, pela sociedade pósindustrial.

A capacitação do homem dentro da era tecnológica tornase, pois, meta básica no processo evolutivo da humanidade; as tentativas de ajustamento de seu comportamento à máquina não conseguirão evitar que suas reações, òbviamente humanas, exerçam influência nos resultados; terão, por isso mesmo, essas reações de ser condicionadas ao aprimoramento do homem.

Como peça principal do conjunto responsável pela atividade estatal, o indivíduo vem sendo considerado de forma enfática mas não exagerada na preparação de qualquer organismo governamental para a execução de seus planos e programas. Certamente atentos a êste aspecto do problema, é que os países em fase de desenvolvimento, como o Brasil, vêm dando atenção especial a Reformas, entre as quais destacamos a Administrativa, procurando colocar a atividade-meio estatal em condições de acompanhar a atividade-fim em seu impulso para reduzir ou anular o hiato tecnológico.

Em trabalho de alta seriedade chegaram ao conhecimento do público, no ano passado, as "Metas e Bases para a Ação de Govêrno", em que são definidos com amplitude os objetivos nacionais dentro de uma linha de ação surgida nos ideais da 
Revolução de 1964 e desenvolvida com apoio no exato conhecimento do papel que desempenha nosso País no processo evolutivo do Terceiro Mundo. Procuramos destacar, naquele documento de grande valor, os esforços do Govêrno com respeito à implementação da Reforma Administrativa.

Considera aquêle trabalho como uma das normas básicas de atuação governamental o "combate à rotina, mediante planejamento objetivo e criador, aperfeiçoamento da execução, definição de prioridades e maior racionalização nas decisões de Govêrno" (p. 9). E acrescenta, à p. 23, que será executada "definida política de valorização de certas categorias sociais de particular significação para o desenvolvimento econômico e social", entre as quais aponta o funcionalismo público. Um dos pontos altos dessa política de valorização é a criação já prevista no Decreto-lei n. 200 - de um sistema de assessoramento superior para os órgãos decisórios do Govêrno. Esse sistema, aliado ao estabelecimento de diretorias técnicas com relativo grau de estabilidade dentro do serviço público, constituirá um corajoso avanço no sentido de dotar o poder público de base administrativa apta a acompanhar, como atividademeio, o processo de desenvolvimento brasileiro orientado pela ação governamental.

Êsse sistema de assessoramento superior já se encontra institucionalizado em países desenvolvidos, como a Grã-Bretanha e a França, com nuanças decorrentes de fatôres ecológicos. La Palombara faz referência, em "Bureaucracy and Political Development" (Princeton University Press, 1963, p. 7), aos homens que compõem essa elite, colocando-os no centro e no cume da gerência administrativa governamental. E Morstein Marx ("The Administrative State", University of Chicago Press, 1957 , p. 63) classifica as diversas áreas de ação dessa elite, dando-lhe um relativo grau de estabilidade dentro do serviço público. A expressão numérica da elite não irá, na opinião de Ferrel Heady ("Public Administration: A Comparative Perspective", Prentice-Hall, Inc., Englewood Cliffs, New Jersey, 1966, p. 22), além de 1 ou $2 \%$ do total dos servidores públicos.

O processo de desenvolvimento brasileiro é, como foi dito acima, orientado pela ação governamental. E não poderia deixar de sê-lo. É uma das características do próprio processo, respaldada no fato de que os resultados dos esforços da iniciativa privada hão de ser dirigidos para o bem comum. E o único agente capaz de fazê-lo é o próprio Estado; com seu poder coercitivo, tem condições para corrigir distorções que, 
vistas pela iniciativa privada, apresentam uma realidade diversa da que é observada pelos olhos do Estado.

No campo da administração pública é constante a preocupação do Govêrno em eliminar vícios e distorções. À página 61 das "Metas e Bases para a Ação de Govêrno" cita, por exemplo, a incapacidade administrativa de nossa estrutura central para coordenar e comandar as ações dentro da "sistemática educacional brasileira", para cuja correção dá "elevada prioridade" ao desenvolvimento da Reforma Administrativa no Ministério da Educação e Cultura (pág. 62).

Difícil se torna um trabalho de seleção dos pontos primordiais em que se baseia uma reforma administrativa, dada a significativa influência de fatôres os mais variados. Limitemonos, aqui, àqueles que consideramos os mais básicos, que se situam nas áreas de pessoal e finanças. Quanto ao primeiro, já fizemos referência à capacitação do homem, à sua valorização funcional e adiantamos, agora, a necessidade de situá-lo dentro de uma carreira, com perspectivas de aprimoramento e sucesso. A segunda área, a de finanças, merece também a preocupação governamental no trabalho ora em análise, principalmente quando defende a manutenção de uma política administrativa voltada, entre outras finalidades, para a austeridade dos dispêndios burocrático-administrativos, cujo instrumento de ação é o "aperfeiçoamento do contrôle de contenção dêsses dispêndios" (pág. 37). Voltam-nos, a êste propósito, nossas considerações iniciais sôbre a influência do comportamento humano na ação administrativa governamental. Os meios do contrôle da contenção dos dispêndios burocrático-administrativos podem, eventualmente, sofrer influência do comportamento individual, surgindo, em conseqüência, variados padrões de aferição da natureza dos dispêndios, qualificáveis menos jurídica que èticamente.

Levantariamos, a esta altura, um problema fundamental, que diz respeito a êsses padrões morais: que forma tomaria um documento no qual se tentasse a uniformização daqueles padrões? Seria viável, dentro da conjuntura sócio-cultural brasileira, a realização de um trabalho dessa espécie? Acreditamos ser êste um campo vasto de estudos, onde seriam primordialmente levadas em conta as características da sociedade brasileira e a sua formação no curso de quatro séculos e meio. Para sermos mais explicitos, perguntaríamos se seria possível, desde logo, se pensar no estabelecimento de um código de ética profissional aplicável às atividades do servidor público. Enten- 
demos por servidor público, neste trabalho, aquela peça fundamental de que o Estado se vale para o desenvolvimento de suas atividades, imbuída da seriedade que é característica, por exemplo, do "civil servant" britânico. Êsse servidor público, como aliás é previsto pela nossa Reforma Administrativa, teria uma formação especialmente destinada à prestação de um serviço público à sociedade.

A formação profissional de uma elite no serviço público o assessoramento superior de que trata o Decreto-lei n? 200 - poderá contribuir, no nosso entender, para a uniformização de padrões morais no exame dos dispêndios quando houver omissão legislativa. Êsse assessoramento, na forma do que está previsto no artigo 121 daquele diploma legal, conta com um Centro de Aperfeiçoamento para os fins de seu recrutamento, seleção, aperfeiçoamento e administração. A nova estrutura moral da elite de que falamos poderia ser moldada através do eficiente instrumento de que legalmente dispõe o Centro de Aperfeiçoamento. Partir-se-ia, após essa primeira etapa, para a base da ação administrativa governamental - o funcionalismo público - que receberia orientação e treinamento adequados à formação de um conceito de aferição moral da natureza dos dispêndios públicos.

Como exemplo do aprêço que demonstramos pela idéia da criação do Centro de Aperfeiçoamento, transcrevemos a tradução de uma das referências que lhe fizemos em trabalho apresentado à "The Victoria University of Manchester", Inglaterra, em dezembro de 1969:

"Mas o passo mais significativo em direção à mudança que pretendemos empreender na mentalidade do servidor público é, em nossa opinião, o estabelecimento de condições tendentes a desenvolver as qualidades funcionais dos altos servidores, ou assessôres. A Reforma Administrativa prevê a criação de um corpo de alto assessoramento no Serviço Público. E um Centro de Aperfeiçoamento já foi criado com o propósito de preparar um "staff" qualificado. Até que ponto pode êsse Centro de Aperfeiçoamento desempenhar o seu papel? De início, necessitamos determinar os niveis nos quais a equipe qualificada deverá atuar. Os Gabinetes dos Ministros; os Órgãos Centrais referidos no capitulo 3.4 dêste projeto - as Secretarias Gerais e as Inspetorias Gerais de Finanças -; os núcleos centrais administrativos de cada Ministério; cada uma das unidades centrais dos diversos Departamentos que compõem o corpo executivo dos Ministérios; cada um dêsses órgãos deve 
depender daquele alto assessoramento. E os homens que representam aquêle assessoramento deverão estar muito bem familiarizados com os principios fundamentais da Administração Federal (planejamento, coordenação, descentralização, delegação de autoridade e contrôle). A maneira pela qual êles podem se familiarizar com aquêles princípios ficará na dependência da forma com que tenham sido recrutados para o Serviço Público. Convencionemos um nome para êsses homens: chamemo-los de "altos assessôres". Jovens estão saindo das Universidades e procurando uma oportunidade para contribuir para o desenvolvimento do País. Vamos recrutá-los e dar-Ihes uma carreira onde possam ter um lugar permanente de trabalho. Expliquemo-Ihes que sua futura carreira não se sujeitará a flutuações políticas. Êles permanecerão em seus cargos mesmo nas ocasiões em que os Ministros forem substituidos. Seu trabalho terá uma base científica e, desde que êles executam politicas, o conhecimento da ciência administrativa contribuirá para uma boa execução de seu trabalho. Os "alto-assessôres" terão a seu cargo uma grande tarefa; êles devem reduzir a larga distância entre os administradores e os supervisores e trabalhadores de nível mais baixo que atendem as recomendações e satisfazem as necessidades administrativas dos dirigentes".

Referido trabalho foi discutido com representantes de países latino-americanos, bem como com o "staff" do "Department of Overseas Administrative Studies" daquela Universidade. Posteriormente, em março de 1970, dêle tomou conhecimento, na Universidade de Glasgow, Escócia, o Dr. Francis Lambert, estudioso de nossos problemas administrativos e detentor do 2 ? prêmio Rio Branco da Casa do Brasil em Londres, por estudo realizado sob o título "Trends in Administrative Reform in Brazil", publicado no "Journal of Latin American Studies", Vol. I, Part. 2 - Novembro de 1969 - Cambridge University Press.

Deixamos, finalmente, aos estudiosos do assunto, a árdua tarefa de equacionar efetivamente o problema, cuja amplitude vem se constituindo em um dos óbices ao funcionamento ideal de nossa máquina administrativa. 